\title{
O CINEMA OCUPA O PÁTIO
}

\author{
Lara Lima Satler ${ }^{1}$, Ana Rita Vidica Fernandes ${ }^{2}$
}

\begin{abstract}
Resumo: O tema deste texto é o movimento de ocupação do Pátio Humanidades, no Campus Samambaia da Universidade Federal de Goiás (UFG). Ações de cultura em diálogo com o ensino e a pesquisa têm sido realizadas no intuito de ocupá-lo, pois até no final de 2017 tinha o tráfico de drogas como articulador de relações sociais. A partir da mobilização de unidades acadêmicas, iniciado pela direção da Faculdade de Informação e Comunicação (FIC/ UFG), na figura da profa. Dra. Angelita Pereira Lima, o Pátio Humanidades possui a partir 2018, um Programa de Extensão e Cultura, o Topofilias, coordenado pela profa. Dra. Rusvênia Luiza Batista Rodrigues da Silva. Com o objetivo de relatar as ações da Aspas Produção Colaborativa, projeto de extensão e cultura vinculado ao Topofilias, este texto adota a metodologia da pesquisa bibliográfica e de relatos discentes envolvidos. Como resultados, pretende-se contribuir para o fortalecimento dessas ações e maior articulação com demais projetos.
\end{abstract}

Palavras-chave: extensão. cultura. universitária. Aspas. cinema.

\section{THE CINEMA OCCUPIES THE PÁTIO HUMANIDADES}

Abstract: The theme of this text is the occupation movement of Pátio Humanidades,
at the Samambaia Campus of the Federal University of Goiás (UFG). Culture actions
in dialogue with teaching and research have been carried out in order to occupy
it, since until the end of 2017 there was drug trafficking as an articulator of social
relations. From the mobilization of academic units, initiated by the direction of the
Faculty of Information and Communication (FIC / UFG), in the figure of teacher
Dra. Angelita Pereira Lima, Pátio Humanidades has as of 2018, an Extension and
Culture Program, the Topofilias, coordinated by teacher Dra. Rusvênia Luiza Batista
Rodrigues da Silva. With the objective of reporting the actions of Aspas Produção
Colaborativa, extension project and culture linked to Topofilias, this text adopts the

$1 \quad$ FIC/ UFG - satlerlara@gmail.com

2 FIC/UFG - anavidica@gmail.com 
methodology of bibliographic research and student reports involved. As a result, it is intended to contribute to the strengthening of these actions and greater articulation with other projects.

Keywords: extension. culture. university. Aspas. movie.

\section{EL CINE OCUPA EL PÁTIO HUMANIDADES}

Resumen: El tema de este texto es el movimiento de ocupación del Patio Humanidades, en el Campus Samambaia de la Universidade Federal de Goiás (UFG). Las acciones de cultura en diálogo con la enseñanza y la investigación se han realizado con el fin de ocuparlo, pues hasta finales de 2017 tenía el tráfico de drogas como articulador de relaciones sociales. A partir de la movilización de unidades académicas, iniciado por la dirección de la Facultad de Información y Comunicación (FIC / UFG), en la figura de la profa. Dra. Angelita Pereira Lima, el Patio Humanidades posee a partir de 2018, un Programa de Extensión y Cultura, la Topofilias, coordinado por la profa. Dra. Rusvênia Luiza Batista Rodrigues da Silva. Con el objetivo de relatar las acciones de Aspas Produção Colaborativa, proyecto de extensión y cultura vinculado a la Topofilias, este texto adopta la metodología de la investigación bibliográfica y de relatos discentes involucrados. Como resultados, se pretende contribuir al fortalecimiento de esas acciones y mayor articulación con otros proyectos.

Palabras clave: extensión. cultura. universidad. Aspas. cine.

\section{INTRODUÇÃO}

Este texto discute sobre a ocupação do Pátio Humanidades com ações de cultura e extensão universitária, buscando compreendê-las a partir de documentos do Conselho Nacional de Educação (CNE/ MEC) e de resoluções da Universidade Federal de Goiás (UFG). Trata-se de um esforço no sentido de apresentar os debates realizados atualmente em torno da temática a fim de oferecer caminhos para que discentes, docentes e técnicos administrativos construam projetos e ações cultura e extensão em diálogo com as políticas extensionistas locais e nacionais. Nota-se que há desconhecimento sobre a cultura e extensão universitárias e, por isso, fez-se necessária a discussão.

Na sequência e, em sintonia com este dossiê, construiu-se relatos do projeto de cultura e extensão Aspas Produção Colaborativa, da Faculdade de Informação e Comunicação (FIC/ UFG), objetivando oferecer uma devolutiva à 
comunidade acadêmica sobre as suas ações. A Aspas Produção Colaborativa é um projeto vinculado ao Programa de Extensão Topofilias desde 2018 e, neste sentido, volta suas ações para contribuir com a ocupação do Pátio Humanidades com ações de cinema e cultura.

\section{Desenvolvimento}

No texto referência para a Audiência Pública sobre as Diretrizes para a Política de Extensão na Educação Superior Brasileira que é um ponto de partida para a Minuta de Projeto de Resolução da Câmara de Educação Superior, do Conselho Nacional de Educação, “Extensão Universitária é um processo interdisciplinar educativo, cultural, científico e político que promove a interação transformadora entre as Instituições de Ensino Superior e outros setores da sociedade, em articulação permanente com o ensino e a pesquisa» (BRASIL, 2018, p. 1).

"No âmbito da UFG, a extensão universitária é o processo educativo, cultural e científico que articulado ao ensino e à pesquisa, de forma indissociável, viabiliza a relação transformadora entre a Universidade e a Sociedade" (PROEC, 2018, s/p). Na instituição, as ações de extensão são propostas pela comunidade acadêmica, podendo ser coordenadas oficialmente por docentes e técnicos administrativos. A aprovação e avaliação das mesmas ocorre por meio das Comissões de Extensão (CAEX), nas unidades acadêmicas, cujos presidentes e suplentes as representam junto à Pró-Reitoria de Extensão da Universidade Federal de Goiás (PROEC/ UFG), tendo assento e voto na Câmara Superior de Extensão e Cultura, instância máxima de deliberação sobre a extensão. De acordo com a Proec,

A extensão tem pautado suas ações por três grandes objetivos: (a) integrar ensino e pesquisa na busca de alternativas, visando apresentar soluções para problemas e aspirações da comunidade; (b) organizar, apoiar e acompanhar ações que visem à interação da universidade com a sociedade, gerando benefícios para ambas; e c) incentivar a produção cultural da comunidade acadêmica e comunidades circunvizinhas. A partir dessas referências, a extensão é desenvolvida no sentido de organizar, apoiar e acompanhar ações voltadas para a educação do cidadão nas áreas de educação pública, educação especial, cultura, lazer e recreação, saúde e meio ambiente, criando mecanismos institucionais que permitam avançar o processo de integração entre a Universidade e diversos setores da Sociedade. (PROEC, 2018, s/p) 
Além disso, as ações de extensão da UFG são regulamentadas pela Resolução Consuni no 3 de 2008, em cujo texto apresenta que "Art. $6^{\circ}$ As ações de extensão deverão envolver, necessariamente, a participação da comunidade externa à UFG" (UFG, 2008, p. 2). Neste mesmo documento, tem-se no "Art. $7^{\circ}$ As ações de cultura poderão realizar-se com a participação das comunidades interna e externa ou somente no âmbito da comunidade interna à UFG" (UFG, 2008, p. 2). A partir disso, a Aspas Produção Colaborativa é um projeto da Faculdade de Informação e Comunicação que conjuga a realização de ações tanto de extensão como de cultura, objetivando estimular troca de conhecimentos sobre a produção e interpretação em cinema e cultura audiovisual. Como o projeto surge? Como tem operado até agora?

\section{O Projeto de Extensão e Cultura Aspas Produção Colaborativa3}

A Aspas Produção Colaborativa ${ }^{4}$ inicia-se como um projeto de extensão desenvolvido por estudantes, docentes em parceria com técnicos interessados em produção e exibição em cinema, vídeo e audiovisual em geral. É fundamental mencionar que a Aspas Produção Colaborativa surge a partir da iniciativa dos discentes Guilherme Fernandes da Silva e Lucas Aleixo, durante a disciplina Cinema Colaborativo, ofertada em 2016, na FIC/UFG.

Desde 2018, a Aspas integra do Programa Topofilias, que objetiva ocupar o espaço do Pátio Humanidades com atividades de extensão e cultura a fim de garantir que espaços universitários sejam ocupados com cultura e extensão ao invés do tráfico de drogas. Dialogando com a perspectiva do Topofilias, o projeto Aspas funciona na perspectiva de estabelecer relações entre atividades curriculares e extracurriculares, possibilitando ampliar conteúdos formativos de estudantes de Comunicação Social - Publicidade e Propaganda, Jornalismo, Relações Públicas, Artes Visuais (licenciatura), Pós-graduação em Comunicação e em Arte e Cultural Visual, mas é aberto aos interessados em cinema e audiovisual, independente de sua área ou curso na UFG. Além disso, há um esforço para se construir trocas entre pesquisas e a extensão envolvendo os temas cinema e cultura audiovisual. O projeto tem atuado:

3 Em 2017, estudantes vinculados à Aspas criam uma página na rede social Facebook. Disponível em:<https://www.facebook.com/aspasprodutora/>. Acesso em: 2 out.2018

4 Em 2018, a Aspas constrói seu site vinculado oficialmente ao da FIC. Disponível em: $<$ https://aspas.fic.ufg.br/>. Acesso em: 27. nov. 2018 
1. A partir de demandas da comunidade interna e externa à Universidade Federal de Goiás, envolvendo produções audiovisuais, sendo elas de videoaulas e videotutoriais, documentários de projetos sociais e culturais, entrevistas, etc.;

2. A partir de projetos autorais propostos pelos integrantes desta rede colaborativa. Em ambos os casos, a produtora se interessa por criar as produções audiovisuais, vivenciando todos os processos de roteiro, produção e pós-produção e também manter canais de difusão dessas produções em streaming, na rede 2.0, tais como o canal da produtora no Youtube e uma Revista Eletrônica ${ }^{6}$ com textos de discentes sobre imagem e audiovisual.

Para tanto, uma série de ações está prevista para o projeto, envolvendo desde mostras para formação de público quanto à ampliação de repertório fílmico até a inscrição de projetos em leis de incentivo à cultura, visando a qualificação das produções. Neste sentido, estudantes e demais colaboradores aprendem por meio da experiência prática envolvendo a ação, pois diante do desafio de cada produção pesquisam sobre o audiovisual e o experimentam, bem como realizam trocas de saberes com os públicos externos. Como objetivos, o projeto Aspas vai proporcionar na prática aos alunos como se utiliza equipamentos, técnicas e o mundo audiovisual, criando projetos para a comunidade. Desta forma viabilizasse o incremento da formação acadêmica com pesquisa e a extensão, assim como o aprofundamento das relações de troca com a comunidade. De acordo com o texto referência para a Audiência Pública sobre as Diretrizes para a Política de Extensão na Educação Superior Brasileira,

Art. $7^{\circ}$ Consideram-se ações de extensão aquelas que se enquadrem nas seguintes modalidades:

I - Programas

II - Projetos

III - Cursos e oficinas

IV - Eventos

5 Aspas Produção Colaborativa. Disponível em: <https://www.youtube.com/channel/ UCAoaKreQoLSFDWKAxQfL9-Q>. Acesso em: 4. nov. 2018

6 Revista Em Streaming. Disponível em: <https://sites.google.com/view/revistaemstreaming/p\%C3\%Argina-inicial >. Acesso em: 27. out. 2018 
V - Prestação de serviços.

Parágrafo único. Serão consideradas ações de extensão se envolverem diretamente comunidades externas à IES e com o protagonismo dos discentes em sua execução, no termos desta Resolução e com as regulamentações próprias. (BRASIL, 2018, p. 3)

Neste sentido, a Aspas busca, por meio de prestação de serviços, cursos e oficinas oferecidos à comunidade externa envolvendo a interpretação audiovisual, formação de público, produção e difusão em cinema e cultura audiovisual. Assim, o Projeto de Extensão da Produtora Colaborativa Aspas se justifica pelo amplo uso do audiovisual no contemporâneo, oferecendo a estudantes, técnicos e docentes oportunidades, dentro da própria universidade, para expandir suas habilidades criativas, técnicas e experimentais em narrativas audiovisuais e difusão na rede 2.0, o que implica no diálogo com a comunidade externa. Uma vez que a Aspas Produtora Colaborativa faz uso das estruturas e dos recursos da Faculdade de Informação e Comunicação (FIC), construiu uma parceria com o Comunica Estúdio ${ }^{7}$ da unidade acadêmica, tendo este como espaço de execução de suas ações. Assim, justifica-se que o projeto usufrui de estrutura capaz de dar aporte às ações que pretende desenvolver.

O projeto de extensão Produtora Colaborativa Aspas realiza as ações em extensão e cultura por dos caminhos metodológicos:

Produção Audiovisual de videoaulas e videotutorais sob demanda interna e externa à UFG.

Estímulo à difusão pública de videoaulas e videotutorais em streamings pela rede 2.0 .

Criação de projetos autorais em audiovisual.

Submissão de projetos autorais da rede colaborativa em leis de incentivo à cultura.

Inscrição de produções audiovisuais em festivais (locais, regionais, nacionais e internacionais) e espaços de exibição audiovisual como museus e galerias.

Produção audiovisual de Cine Críticas de cinema brasileiro / cinema de museu.

7 O Comunica é um laboratório da Faculdade de Informação e Comunicação que atende às disciplinas de fotografia e audiovisual, bem como abarca projetos de pesquisa e extensão que objetivam a produção. Disponível em: <https://comunica.fic.ufg.br>. Acesso em: 7. out.2018 
Difusão pública de Cine Críticas de cinema brasileiro / cinema de museu em streamings pela rede 2.0.

Organização de Mostras a partir de parcerias internacionais como a AO NORTE - Associação de Produção e Animação Audiovisual responsável pela organização do Encontro de Cinema de Viana do Castelo, Portugal.

Aspas em Revista - Revista Eletrônica da Produtora Colaborativa ${ }^{8}$, contendo os seguintes enfoques:

Cine Críticas de cinema, séries e TV Aberta à participação de estudantes, docentes e técnicos, as críticas podem ser enviadas à Revista Eletrônica e visam estimular a ampliação de repertório, especialmente para o cinema brasileiro. Difundidas na rede 2.0, as críticas são de acesso público.

Aspas Conhecendo a UFG Aspas - Conhecendo a UFG é uma ação que visa oferecer informações aos recém-ingressantes da Universidade Federal de Goiás sobre as oportunidades que a instituição lhes proporciona como Intercâmbio no Exterior, Mobilidade Estudantil, Monitorias, Campos de Estágio, etc.

Por meio de entrevistas com representantes da UFG, as informações publicadas em revista eletrônica na rede 2.0 e também expostas em escolas do ensino médio. Considerando a revista eletrônica Aspas em Revista, o Projeto de Extensão e Cultura da Produtora Colaborativa Aspas é pertinente na medida em que busca levar aos espaços de ensino da UFG o diálogo com a pesquisa realizada na Pós-graduação, uma vez que os Intercâmbios podem ocorrer em contextos de aula, grupos de estudo, grupos de pesquisa e outros, permitindo que a reinvenção da docência, ao aproximar a pesquisa de processos de aprendizagem diversos, como os que ocorrem na extensão (DEMO, 2011).

Aspas Intercâmbios com a Pós-Graduação': O Projeto Intercâmbios opera como mediador entre as pesquisas realizadas pelos pós-graduandos que estudam Imagem e os estudantes de imagem, na graduação da UFG. Ao criarmos um banco de resumos de pesquisa e disponibilizarmos em plataformas digitais, na Revista Aspas, daremos visibilidade às pesquisas em curso juntos aos docentes da UFG a fim de propiciar convites aos pós-graduandos para contribuir com disciplinas que busquem estimular a investigação com/ sobre/ em / a partir da imagem. Assim, o projeto se coloca como mediador entre a

\footnotetext{
8 Ação em construção.

9 Ação em construção.
} 
graduação e a pós-graduação, de modo que os professores interessados em convidar pós-graduandos do programa possam fazê-lo a partir do conhecimento dos resumos de suas pesquisas.

Aspas Social é uma ação que visa construir clipping de projetos sociais em Goiânia, Brasil e exterior, buscando realizar entrevistas com autores de projetos sociais, representantes de Ongs e Oscips. Em diálogo com a Aspas Cultural: É uma ação que visa construir clipping de ações culturais em Goiânia, Brasil e exterior, buscando realizar entrevistas e debates com produtores culturais.

\section{A perspectiva estudantil sobre a Aspas Produção Colaborativa}

Neste item, tornou-se imprescindível apresentar trechos dos Relatórios Discentes de Extensão, escritos no Sistema de Gestão Acadêmica, como processo avaliativo de estudantes oficialmente selecionados pelo Programa de Voluntários de Extensão e Cultura (PROVEC), da UFG. Embora a equipe envolvida continha outros membros, as três estudantes abaixo escreveram os relatórios parciais e finais, no primeiro ano de existência do projeto de extensão e cultura Aspas Produção Colaborativa.

O projeto Aspas é de suma importância para os alunos que prezam pela vertente do audiovisual dentro da FIC, principalmente para os alunos de Publicidade e Propaganda, onde é pouco praticado e há relevância entre os alunos. Em âmbito social o projeto serve à comunidade não só universitária, mas ao público geral já que os conteúdos desenvolvidos na Aspas são de caráter interativo e exibidos tanto na TV UFG (que é transmitida por sinal aberto de televisão) quanto em plataformas digitais de vídeo como Youtube, sendo que as produções envolvem tópicos de interesse ao públicogeral. As metas para o primeiro semestre foram concluídas com êxito e a maior parte do conteúdo foi de qualidade, já para os alunos componentes do projeto, o mesmo foi extremamente construtivo pois desenvolveu não só no âmbito da pesquisa como também no quesito prático do audiovisual o qual está em falta para os alunos de Publicidade e Propaganda. No geral, o projeto seguiu bem o planejado inicialmente, apesar de ter alguns desvios devido a dificuldade dos alunos em desenvolver os conteúdos por falta de experiência na área, principalmente com a edição de vídeos, mas esse problema foi sendo solucionado quando os alunos obtiveram maior contato com o técnico de edição de vídeo do Estúdio Comunica, em que o mesmo dava orientações para os diversos problemas. A Aspas é extremamente construtiva para o aluno em termos acadêmicos tanto práticos quanto teóricos por desenvolver de forma ampla a capacidade de percepção do aluno diante dos conteúdos produzidos e por implicar a necessidade de conhecimento prático dentro da área. Para os projetos futuros é esperado que continuemos com a produção do inter programa "CINESTESIA", que existam novas produções e a manutenção das mídias sociais no intuito de divulgar o projeto para outros alunos presentes na FIC e com interesse no audiovisual. (MASSIMINA, 2018, p.1) 
Criamos um canal no YouTube para armazenar e expor os materiais produzidos pela Aspas e parceiros. Iniciamos a construção de uma página para a produtora nos moldes solicitados pela UFG. Colaboramos com a execução de uma oficina que, visando a elaboração de uma pesquisa acadêmica, trabalhou com crianças a produção de vídeo na era digital. Participamos na construção da campanha "Eu tenho um sonho", elaborada pelo GT em Ações Afirmativas da Faculdade de Informação e comunicação. Capturamos as imagens, editamos e finalizamos o material que foi concebido como campanha de conscientização para o mês da consciência negra. Idealizamos e construímos o interprograma Cinestesia afim de estreitar nossas relações com a TV UFG e de nos empenharmos na construção de um material de qualidade. O episódio piloto já foi gravado. Produzimos também para a TV UFG vinhetas que farão parte da programação da emissora nos intervalos entre programas. Buscamos também conhecer as pessoas envolvidas no programa Viver Ciência, as produções e a estrutura do curso de Cinema na Universidade Estadual de Goiás, os bastidores da TV UFG, a fim de nos inspiramos com o que está sendo realizado em Goiânia e de buscar parcerias para futuros projetos. Em parceria com o Aram, projeto de extensão voltado à fotografia, coordenado pela professora Dra. Ana Rita Vidica, participamos da construção de um documentário que tem como tema a Art Déco da cidade de Goiânia. O Aram entrou com uma seleção de fotografias tiradas de forma coletivas e a Aspas abriu um chamado público para pessoas interessadas em falar sobre sua relação com a arquitetura da cidade. Criamos um cenário com as fotografias reveladas, preparamos os equipamentos de filmagem, iluminação e captação de aúdio e recebemos os convidados no dia 01 de maio de 2018, na Vila Cultural Cora Coralina. Após as gravações foi feita a roteirização e edição do documentário. Afim de tornar público as ações da Aspas realizamos uma Mostra para compartilhar com a comunidade alguns trabalhos da produtora. A “Aspas Mostra Diversos" aconteceu no dia 05 de junho de 2018, no auditório multimídia da Vila Cultural Cora Coralina e exibiu o documentário Art Déco dirigido por Guilherme Fernandes; Corte Final, um curta metragem dos alunos Itamar Franco, Rute Xavier; Natureza e De onde vêm as ideias, vinhetas produzidas por Vitória Massimina e Victória Arantes, respectivamente. O público teve a oportunidade de conversar com os realizadores ao final das exibições, pôde tirar dúvidas sobre o processo de produção, as técnicas e equipamentos utilizados e sobre o funcionamento do projeto de extensão. Em sequência a produtora cultural Marci Dornelas participou de uma roda de conversa mediada pela professora Lara Satler. Marci é produtora cultural do Festival Internacional de Artes Cênicas Goiânia em Cena, Quasar Projeto Dança na Cidade e Festival de Cinema Brasileiro Festcine, entre outros projetos. Ela falou sobre a trajetória da sua carreira, sobre os projetos que desenvolve e as perspectivas para ingressar no mercado goiano de produção, além de responder às dúvidas dos participantes. [...] De maneira geral, a equipe envolvida no projeto de extensão Aspas, conseguiu conversar com uma pluralidade de conteúdo e de pessoas de maneira bastante enriquecedora. Monitores, coordenadores e voluntários aprenderam a importância de honrar compromissos dentro de uma produção colaborativa. Contribuímos com projetos que se relacionavam com os interesses pessoais e simultaneamente conseguimos atender algumas demandas da nossa universidade. [...] Conseguimos trabalhar nossos objetivos iniciais e pensar com mais clareza nas outras demandas do nosso plano de trabalho. Percebemos a importância do envolvimento de todos os participantes 
e do compromisso com as responsabilidades que nos são atribuídas. A falta de estrutura para a execução dos projetos, de um local adequado para nossos encontros e reuniões e de equipamentos por vezes desmotivou colocar em prática algumas ideias e atender algumas solicitações que nos foram feitas. No balanço final enxergamos que produzimos uma quantidade interessante de conteúdo mas que poderíamos ir bem mais longe com mais empenho individual e compromisso com o coletivo. (ALMEIDA, 2018, p.1-2)

Os roteiros foram produzidos em uma plataforma online e gratuita chamada Celtx. O Celtx é um programa de pré-produção seja de um filme, peça teatral ou animação. É um processador de textos especialmente para roteiros. E a pós produção, especificamente a montagem, foi feita no Adobe Premiere e Adobe After Effects. Além disso, nossa visita a TV UFG nos ajudou a tomar as medidas necessárias para a veiculação do material, como por exemplo os direitos autorais sobre a trilha, a imagem e, também, os documentos de autorização de uso de imagem, quando necessário. Além disso, o contato com a TV UFG nos fez perceber os cuidados necessários para que um material possa ser veiculado na TV, como por exemplo a qualidade de som e iluminação. Além disso, no estúdio de som da FIC, ao gravar a locução uma das vinhetas, aprendemos o ritmo certo para a locução e também como tratar o som na mesa, logo após a gravação. Também, na gravação do piloto do interprograma Cinestesia, tivemos a presença de uma professora de fotografia para nos ensinar e amparar na iluminação e enquadramento. [...] A Aspas Produtora Colaborativa é a primeira produtora audiovisual da FIC. É um projeto muito recente, porém inovador. A FIC possui duas agências de publicidade: a Inova (Agência Experimental) e a Ponto (Agência Júnior). A Aspas nasceu para suprir a carência que alunos interessados pela área do audiovisual têm dentro do curso. Além disso, para complementar, introduzir e incentivar a colocar em prática o que foi aprendido nas matérias de Audiovisual 1 e ll. Além de outros cursos ofertados como Cinema Colaborativo. Sua relevância social é oferecer para a comunidade um serviço de audiovisual barato ou até gratuito, visto que é um ramo muito caro, e isso o torna mais acessível para quem precisa dessa demanda. (ARANTES, 2018, p. 2)

\section{Projeto Aspas e o Pátio Humanidades}

Dentro da perspectiva das ações culturais do Projeto Aspas, a partir de diálogos com o currículo de Comunicação Social - Publicidade e Propaganda, foi realizada a Feira Troquei. Em parceria com o ensino da disciplina de Produção Cultural, em 2018, as ações da Feira Troquei traduzem o desafio docente em diálogo com o protagonismo estudantil em nome de uma atuação sociocultural que ao mesmo tempo ocupe o Pátio Humanidades, promovendo ações culturais, que extrapolam os muros da universidade.

Assim, a proposta constituiu em realizar uma feira com expressões culturais a escolha dos discentes a fim de que as barracas pudessem trocar suas 
ofertas por roupas em boas condições, que foram levadas para instituições de apoio à populações de baixa renda. Foi oferecida como opção o Setor de Voluntariado do Hospital Araújo Jorge, Setor Universitário, Goiânia, Goiás, mas foi respeitada a escolha dos próprios discentes quanto à instituição, bem como a entrega à eleita pelos mesmos.

Ficura 1: Flyer de divulgação para redes sociais. Autoria de estudantes da Franco ]r. et al, 2018.

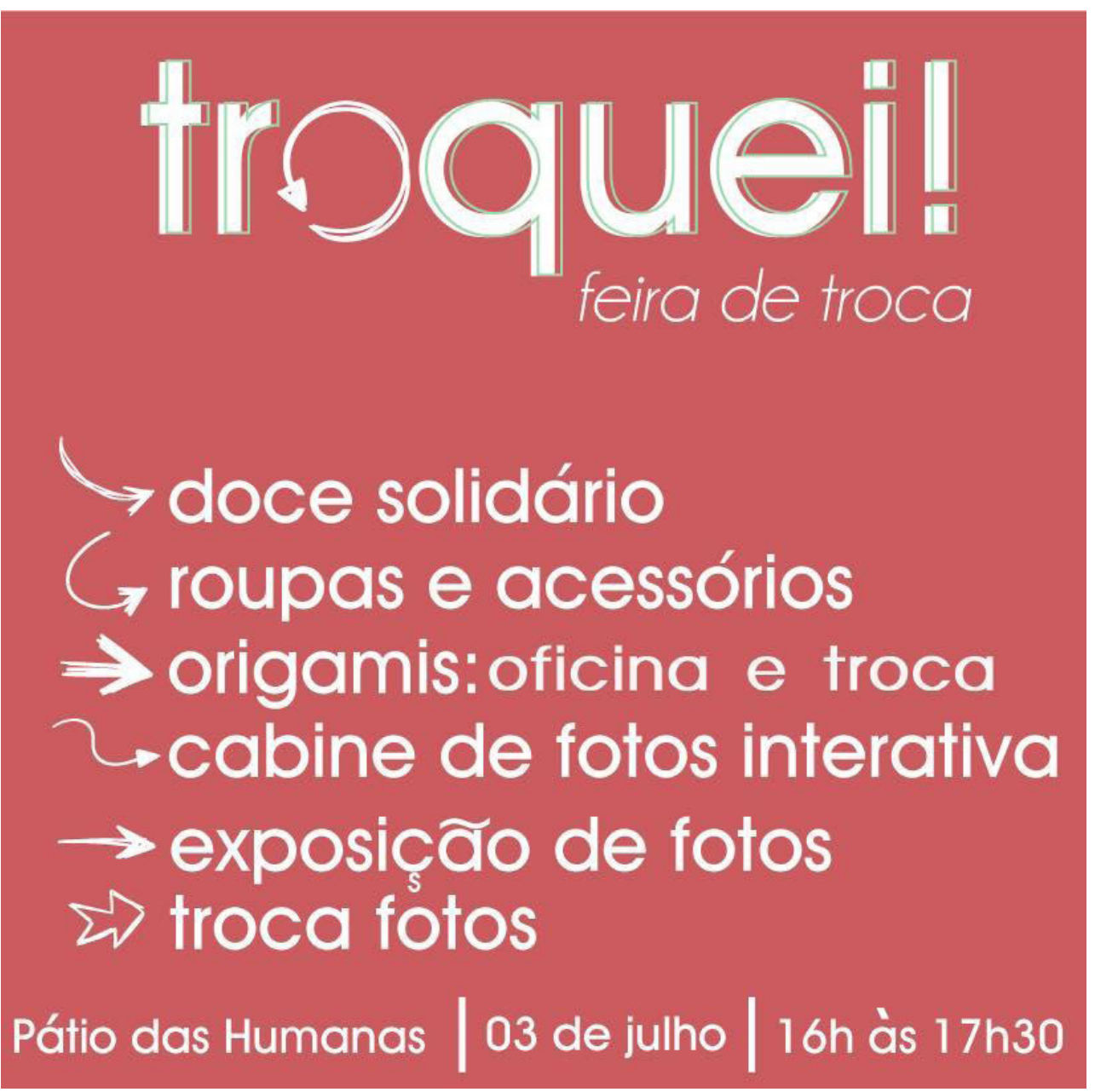

Fonte: Trabalho de CAMPo, PÁtio Humanidades, NOV. 2018

Neste sentido, grupos de estudantes selecionaram expressões culturais nas quais construíram seus protagonismos a fim de participar da ação. Foram criadas barracas que elegeram a fotografia, a culinária, o artesanato, a moda, a publicidade e a educação superior como expressão cultural. A figura é uma montagem de alguns posts de redes sociais da divulgação disponível na página 
do evento, ocorrido no Pátio Humanidades. De acordo com os estudantes que conceberam a proposta,

A comunicação visual da Feira Troquei! é composta por cores sólidas, imagens em vetor que fazem referência a identidade visual da série americana Glee, que faz parte do repertório dos jovens que são público alvo do evento. A linguagem utilizada é simples e informal, deixando a comunicação mais leve e humana. As estratégias utilizadas para comunicar o público foram posts no Facebook, um evento no Facebook e um post viral de WhatsApp. (FRANCO Jr et al, 2018, s/p)

Considerando que os discentes participantes dessa ação cultural são matriculados no curso de Comunicação Social - Publicidade e Propaganda, a campanha de divulgação e da concepção da identidade visual do evento é um exercício desejável para seus discentes. Além disso, o desafio de conhecer instituições que pudessem receber as doações e também as ações culturais exigiram dos discentes a construção de saberes mais do que técnicos. Tal perspectiva buscou sintonia com o artigo $6^{\circ}$ do texto referência para a Audiência Pública sobre as Diretrizes para a Política de Extensão na Educação Superior Brasileira,

Art. $6^{\circ}$ São Princípios da Extensão na Educação Superior, que estruturam sua concepção e prática:

I - a contribuição na formação integral dos estudantes, estimulando formação do estudante como cidadão crítico e responsável;

II - o estabelecimento de diálogo construtivo e transformador com os demais setores da sociedade;

III - a promoção de iniciativas que expressem o compromisso social das IES, em consonância com as políticas ligadas às diretrizes para a educação ambiental, educação étnico racial, direitos humanos e educação indígena;

IV - a promoção da reflexão ética sobre a dimensão social do ensino e da pesquisa; $\mathrm{V}$ - o incentivo à atuação da comunidade acadêmica e técnica na contribuição ao enfrentamento das questões da sociedade brasileira, inclusive por meio do desenvolvimento econômico social e cultural;

VI - o apoio em princípios éticos que expressem o compromisso social de cada IES; VII a atuação na produção e construção de conhecimentos voltados para o desenvolvimento social, equitativo, sustentável, atualizado e coerente com a realidade brasileira. (BRASIL, 2018, p. 3) 
Ficure 2: Flyer da Feira Troquei no Pátio Humanidades. Autoria de FRANCO Jr et al, 2018.

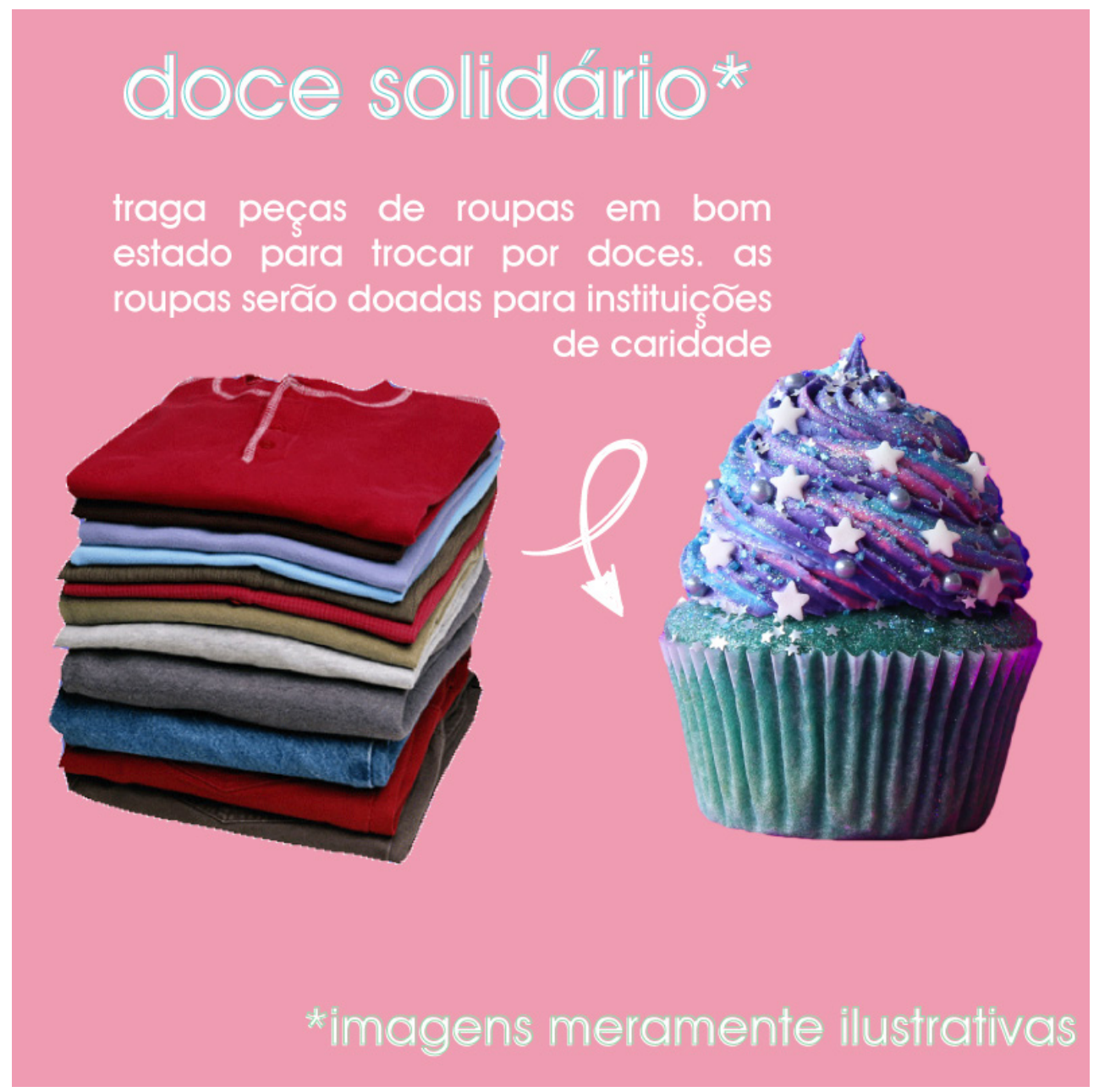

Fonte: Trabalmo de CAMPo, PÁtio Humanidades, NOV. 2018

Ressalta-se que na disciplina de Produção Cultural, parte-se do conceito de cultura como um sistema simbólico, ou seja, como um código de símbolos partilhados socialmente (LARAIA, 2008). Neste sentido, estimulou-se que discentes adotassem expressões culturais partilhadas entre si para levar à Feira Troquei. O interesse pela cultura nipônica guiou a oficina de origamis, "a arte do Origami através da possibilidade de trocar essas peças da cultura nipônica entre os participantes da feira, ou aprender a fazer os mesmos contando com a ajuda de um instrutor destinado a uma seleção de origamis específicos", como argumenta o grupo, por meio deste trecho de relatório (GOULART et al, 2018, s/p). 
Também foi o interesse por fotografia por parte de outro grupo de discentes que fez emergir a ação da cabine fotográfica. Segundo relatório discente do grupo,

A ideia do evento era que qualquer pessoa pudesse trocar qualquer coisa com os organizadores das barracas em troca dos produtos por eles oferecidos. No nosso caso, a ideia dada por nós era a criação de uma cabine fotográfica. Esta foi confeccionada com papelão, TNT e isopor basicamente. Com as cores da bandeira brasileira pelo evento ter acontecido em meio à Copa do Mundo de 2018. (MELO et al, 2018, s/p)

O interesse pela cultura gastronômica e a habilidade em culinária desses dois grupos de discentes cujos relatórios se encontram a seguir possibilitaram a criação de ações culturais permeadas pela doação do próprio tempo e investimento financeiro para sua execução.

A ação cultural "Doce Solidário" tem uma proposta simples: dar um pedaço de bolo a quem doar uma ou mais peças de roupa (infantis, femininas ou masculinas) em bom estado. Considerando que a maioria das pessoas gosta de doces e no período da tarde procura algum local para lanchar no campus, pensamos em estimular as doações a partir da troca do(s) item(s) por um pedaço de bolo. O objetivo da ação cultural é arrecadar peças de roupa em bom estado para serem doadas na Igreja Nossa Senhora da Guadalupe, que repassa as doações para as pessoas carentes da comunidade e para outras instituições de caridade que precisem. [...] A ação durou pouco tempo (cerca de apenas uma hora) e contou com uma divulgação simples, mas, mesmo assim, o resultado foi bastante positivo. Muitas pessoas ficaram interessadas e recebemos tantas doações que conseguimos encher a caixa grande que havíamos levado. Foram arrecadadas peças de roupa masculinas e femininas, porém nenhuma peça infantil. Em resumo, com um pequeno valor investido para confecção dos bolos (menos de $\mathrm{R} \$ 30,00$ ), foi possível arrecadar 37 peças. Ações de arrecadação de itens para doação geralmente demoram mais de um dia para conseguir essa quantidade de peças, por isso, consideramos que tivemos um ótimo resultado. Aprendemos que é possível estimular as pessoas a serem solidárias e fazerem doações fora das épocas mais comuns (como Natal, Páscoa e Dia das crianças), e que uma maneira eficaz para esse incentivo é através de uma troca que beneficie ambos os lados. (SALES et al, 2018, s/p)

Durante a Feira Troquei, realizada no Pátio Humanidades, no dia 3 de julho, às 16 horas, levamos para esse ambiente de trocas algo que valoriza a produção popular caseira - não industrializada - e têm um valor cultural quase imperceptível: o brigadeiro. Um quitute simples de fazer e que, em parte por esse motivo, é muito preparado e apreciado dentro de casa por pessoas de todas as idades e classes sociais e faz parte dos nossos costumes mais populares. Nosso objetivo com essa ação era tornar visível um produto cultural tão próprio da nossa gente e tão importante, tanto na nossa culinária popular quanto na nossa economia - é 
um produto muito utilizado por profissionais informais para conseguir se subsidiar e criar condições de inserção social pelo trabalho e pela renda. (LOPES et al, 2018, s/p)

Figure 3: Flyer da Feira Troquei no Pátio Humanidades. Autoria de FRANCO Jr et al, 2018.

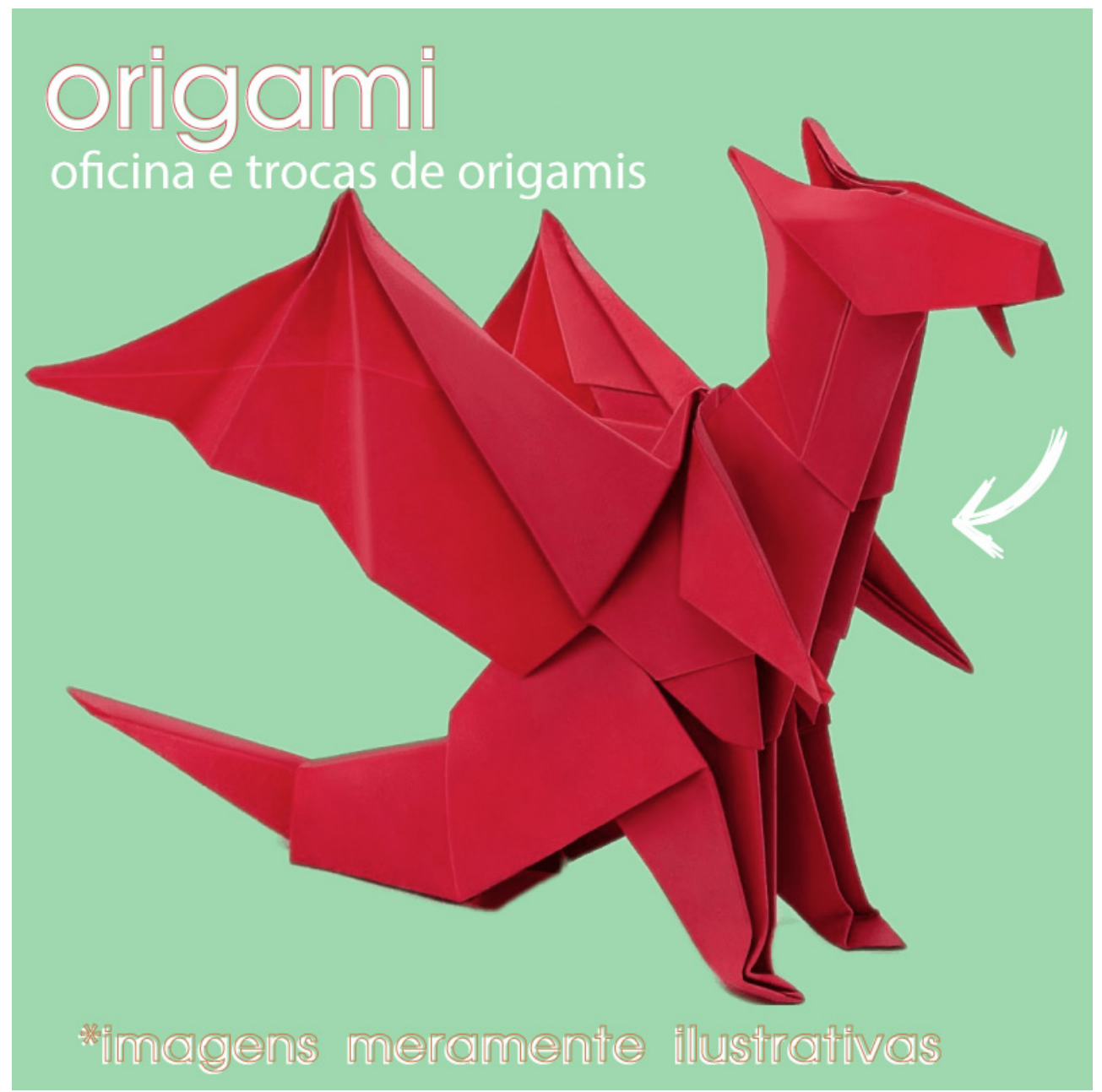

Fonte: Trabalmo de Campo, Pátıo Humanidades, NOV. 2018

É preciso observar que embora grande parte da ação tenha ocorrido no Pátio Humanidades, dois grupos se interessaram por realizar sua prática em produção cultural, fora deste espaço. Uma delas foi a organização de shows de bandas universitárias, durante o intervalo das aulas, tendo ocorrido ao lado do Restaurante Universitário, no Campus Samambaia da UFG (AMUI et al, 2018). E a outra ação ocorreu na biblioteca do Colégio Estadual Ary Ribeiro Valadão filho, localizado na Vila Finsocial. Tratou-se de uma Roda de Conversa organizada para 
que três universitários egressos desta escola voltassem a ela para trazer suas experiências com estudantes do terceiro ano, do ensino médio. De acordo com as discentes participantes desta ação, em seus relatórios,

Uma conversa com alunos do terceiro ano do ensino médio, com idades entre 16 e 18 anos e pertencentes a classes sociais de $\mathrm{C}$ a E, sobre os processos de seleção para a entrada em um curso superior e a vida após a escola. Com a participação de três alunos que já estudaram nesta instituição de ensino foi possível ter uma perspectiva de quem já esteve no lugar dos ouvintes. [...] Além de falar sobre os meios de entrar em instituições de ensino superior, as diferenças entre a escola e a faculdade e as preparações para os processos de seleção, também foi possível ter uma visão de quem já esteve no lugar daqueles alunos, que poderão enfrentar receios ao se depararem com colegas de classe vindos das melhores escolas particulares e com uma base de ensino muito mais completa. As diferença s socioeconômicas também foram envolvidas na conversa a partir de relatos dos universitários. (VILELA et al, 2018, s/p)

Outra ação cultural realizada no Pátio Humanidades foi a exposição fotográfica, oriunda da parceria de duas disciplinas de graduação, Iniciação Acadêmica - Práticas de Pesquisa e Introdução à Fotografia, bem como dos dois projetos de extensão e cultura Aspas Produção Colaborativa e Projeto Aram, todos na Faculdade de Informação e Comunicação (FIC/ UFG).

A exposição apresenta narrativas visuais contendo composições de até dez imagens construídas a partir de pesquisa documental sobre fotógrafos de referência. Houve também como desafio proposto o tema "cidade". Dentro deste grande tema, cada um dos doze grupos deveria construir um recorte considerando a pesquisa bibliográfica (STUMPF, 2005) discutindo fotografia, cidade e técnicas fotográficas. Os trabalhos abordaram temas como afetividade, memórias, solidão, decadência do zoológico, tecnologia, feiras livres, personagens urbanos, muros e grades, etc. 
Ficure 4: Programação Cultural do $15^{\circ}$ Conpeex, 2018.

\section{PROGRAMAÇÃO GERAL}
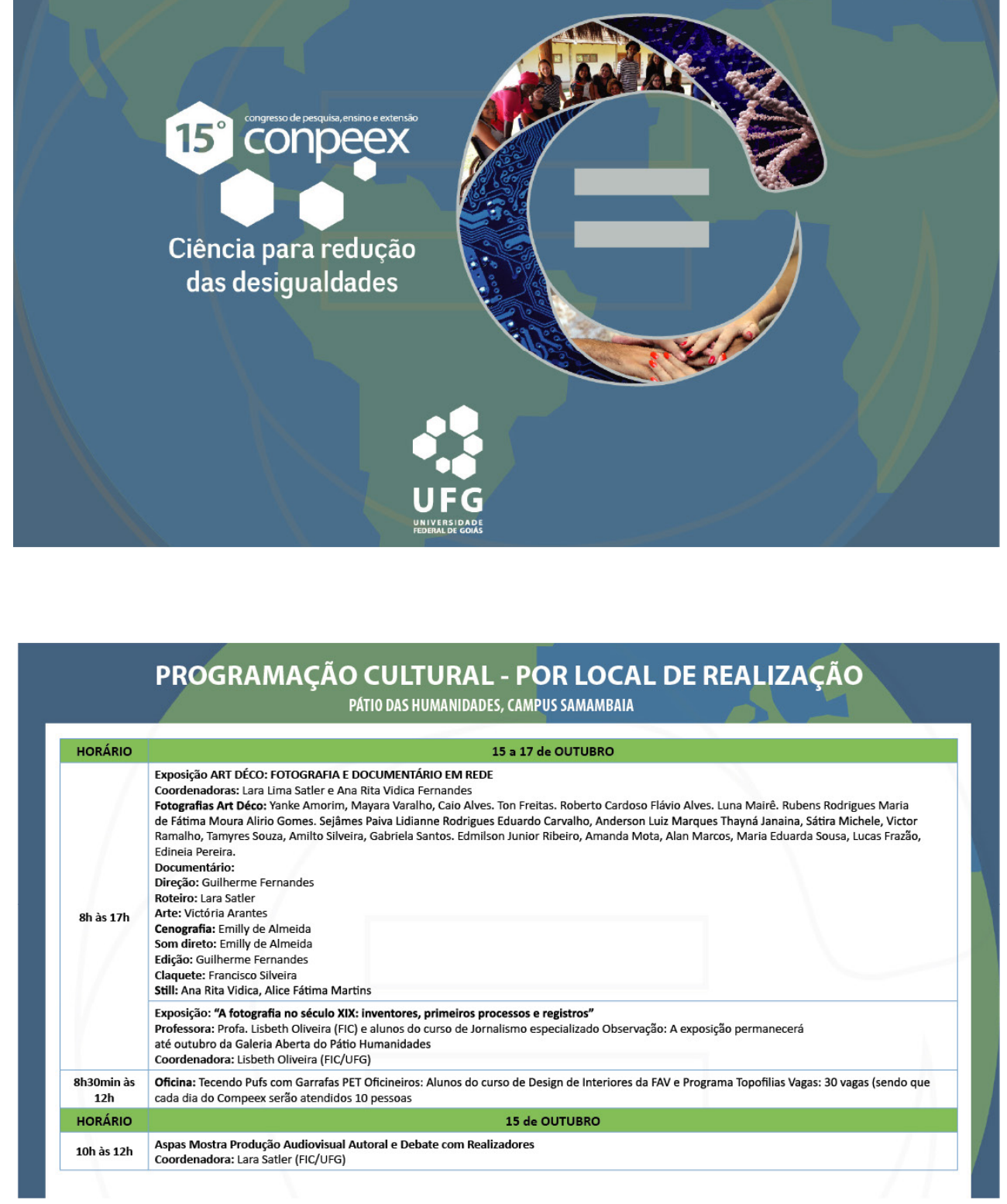

Fonte: Trabalmo de CAMPo, PÁtIo Humanidades, NOV. 2018 
Ficure 5: Divulgação Aspas Mostra e Roda de Conversa, no Pátio Humanidades, 2018.

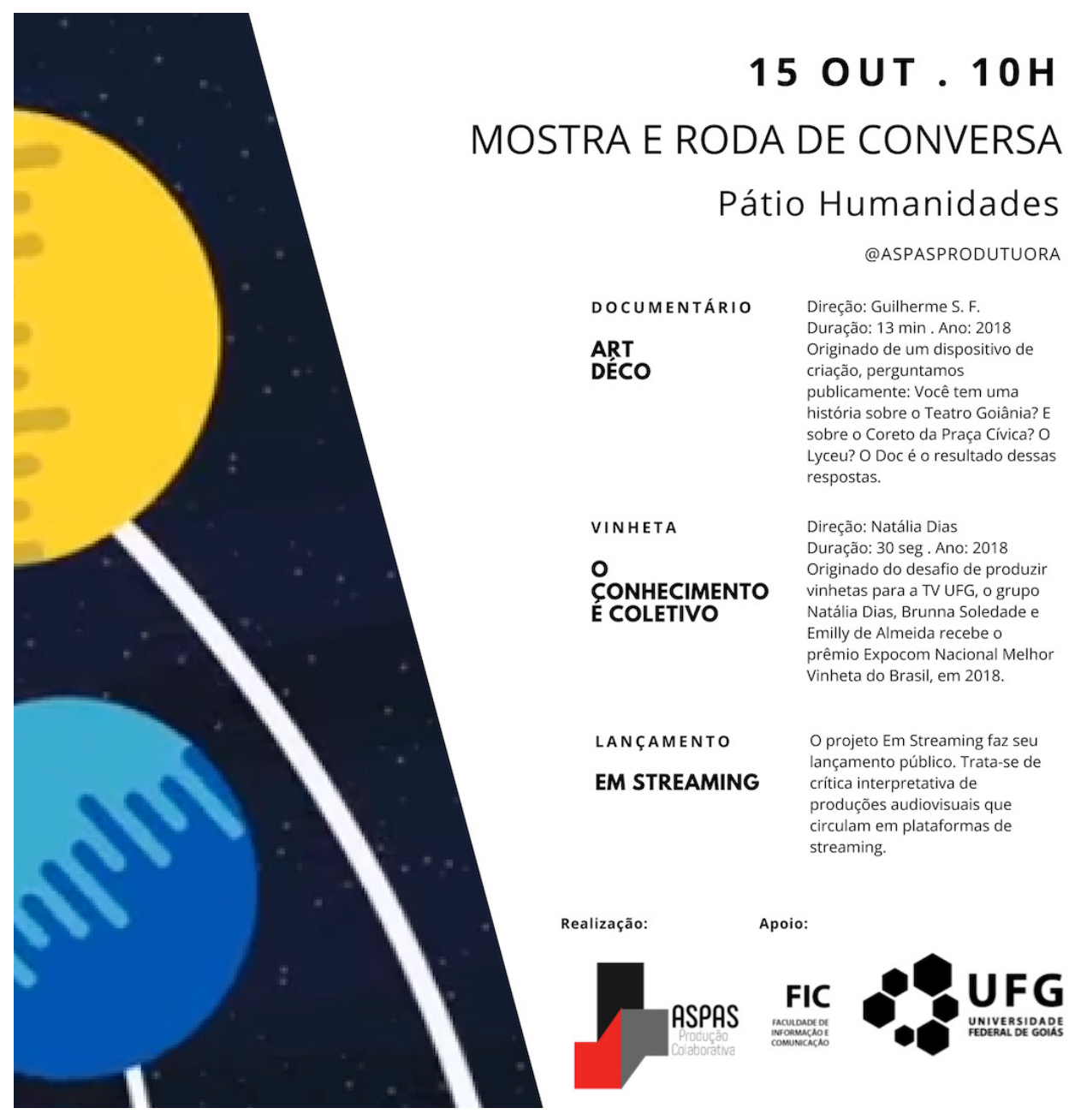

Fonte: Trabalmo de Campo, Pátio Humanidades, NOV. 2018

A ação cultural Aspas Mostra Produção Autoral e Debate com Realizadores foi realizada durante o $15^{\circ}$ Congresso de Ensino, Pesquisa e Extensão - Conpeex, em 2018, conforme figura. Tratou-se de uma mostra que cumpre o papel de divulgar o prêmio das discentes Natália Dias, Brunna Soledade e Emilly de Almeida, vencedoras do Expocom, na etapa Regional e também Nacional. O prêmio afirma a qualidade dos trabalhos realizados em disciplinas, em cursos da Comunicação Social e Cinema de todo o país (DIAS et al, 2018a, 2018b). A premiação é para apenas o melhor trabalho entre todos os concorrentes do Brasil. Foi na categoria vinheta que as estudantes trouxeram para a FIC/UFG o troféu, em 2018, sendo neste ano o único trabalho que a unidade teve premiação nacional. Durante a Mostra, a vinheta foi exibida e 
as estudantes responderam ao público presente sobre os processos de criação. Ressalta-se que a vinheta foi produzida para ser veiculada na TV/UFG.

A Aspas também submeteu ao comitê avaliativo da Mostra Cultural do $15^{\circ}$ Conpeex, uma das suas produções autorais, o documentário Art Déco, dirigido pelo estudante Guilherme Fernandes, da FIC/UFG. Sendo aprovado, o documentário foi exibido, durante o evento, bem como as fotografias que compuseram o cenário, foram expostas no Pátio Humanidades.

Por fim, vale ressaltar que o protagonismo estudantil na apresentação do pôster sobre as ações de extensão e cultura da Aspas Produção Colaborativa. O resumo do trabalho foi aceito pelo comitê científico da Feira de Comunicação e Informação - Feicom, em 2018, e apresentado no Pátio Humanidades. A proposta do texto foi apresentar à FIC devolutivas sobre o projeto de extensão e cultura, de modo a discutir sua proposta, os objetivos, as atividades desenvolvidas, como pode ser visto na figura 6. Afinal, de acordo com o artigo 17 do texto referência para a Audiência Pública sobre as Diretrizes para a Política de Extensão na Educação Superior Brasileira “as ações de Extensão serão registradas na documentação do estudante como forma de reconhecimento da Extensão em sua dimensão formativa" (BRASIL, 2018, p. 5). 
FICURE 6: Pôster apresentado durante a Feicom, no Pátio Humanidades, 2018.
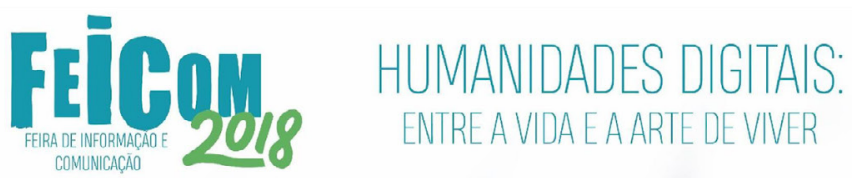

18 e 19

DE OUTUBRO DE 2018

COMUNICAC̄ĀO

\title{
ASPAS - PRODUTORA COLABORATIVA
}

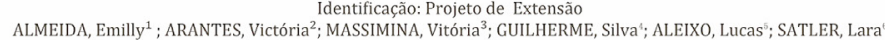

1.Emilly César (Comunicação Social- Publicidade e Propaganda, Universidade Federal de Goiás, UFG); almeida.yx@email..com 2.Victória Arantes (Comunicaçăo Social- Publicidade e Propaganda, Universidade Federal de Goiás , UFG); arantesfv@email..com 3.Vitória Massimina (Comunicação Social- Publicidade e Propaganda, Universidade Federal de Goiás, UFG); massimina.v@email..com 4.Guilherme Silva (Comunicação Social- Publicidade e Propaganda, Universidade Federal de Goiás, UFG);94guilhermefernandes@email.com 5.Lucas Aleixo (Comunicação Social- Publicidade e Propaganda, Universidade Federal de Goiás, UFG);lucasaleixomaia10@email..com 6.Orientador: Lara Satler (Comunicaçăo Social- Publicidade e Propaganda, Universidade Federal de Goiás , UFG); satlerlara@email..com

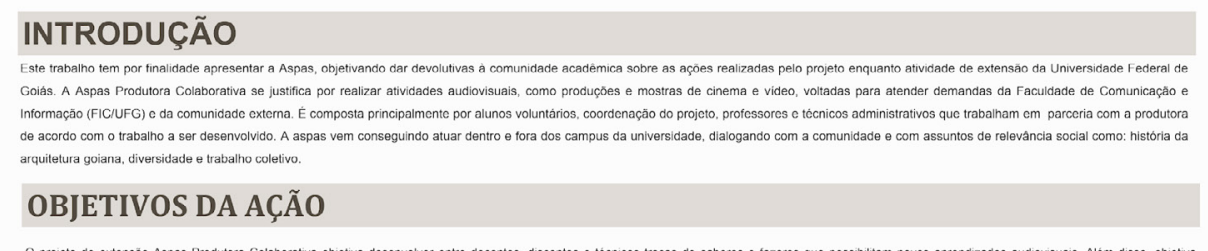

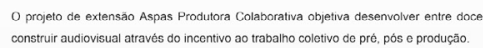

\section{ATIVIDADES DESENVOLVIDAS}

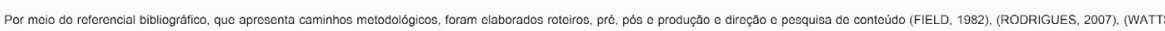
1990). Como resultados alcançados, tomos que cada açăo foi avaliada o discutda do forma colettva, rospoitando a disponibilidado, os valores o a criatvidado do grupo para accitar ou recusar demanda externas. Assim, criou-se urm canal no YouTube para armazenar e expor os maleriails produzidos pela Aspas e parceirios. Iniciou-se a construşăa de uma página para a produtora nos moldes solicitados pela

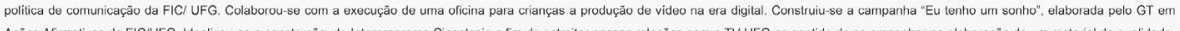

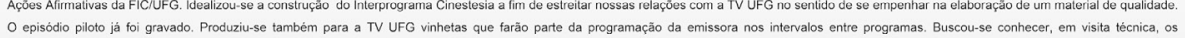

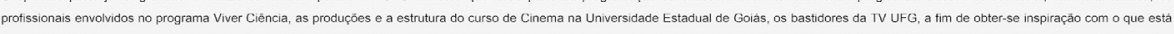

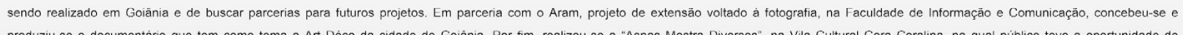

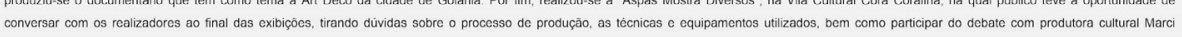

\section{CONSIDERAÇÕES FINAIS}

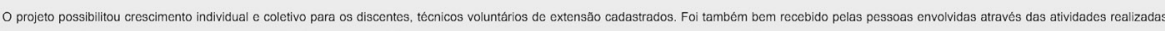
As parcerlas fetias ao longo do plano de trabalho foram contribuiģoes valorosas para a produtora e seus partcipantes, possibilitando estrettar de laços com outros setores da universitade enquanto

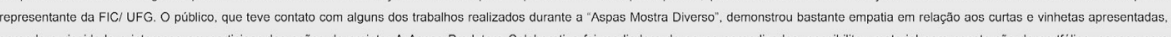

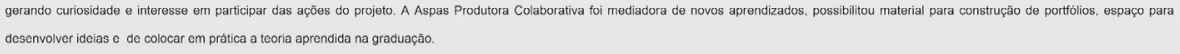

\section{REFERÊNCIAS}

FIELD. S. Manual do roteiro. Rio de Janeiro: Objetiva, 1982

RODRIGUES, C. 0 cinema $\theta$ a produçăo. Rio de Janeiro: Lamparna, 2007.

WATTS, H. On Camera. São Paulo. Summus, 1990.

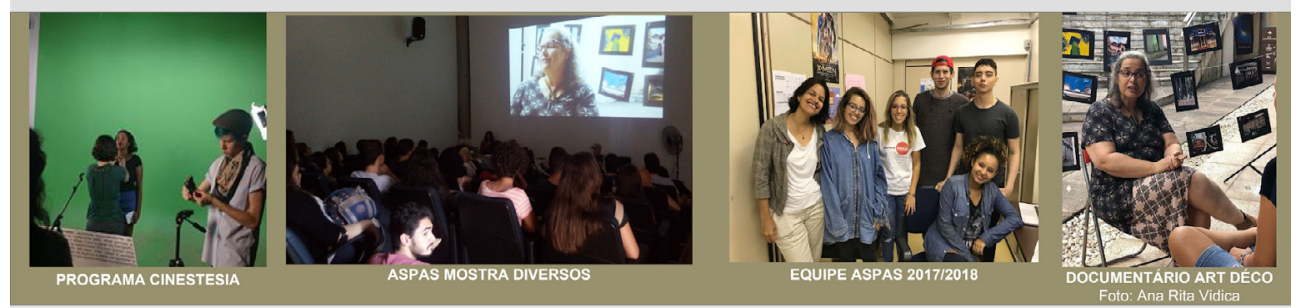

Fonte: Trabalho de Campo, PÁtio Humanidades, NOV. 2018 


\section{CONSIDERAÇÕES FINAIS}

Pode-se iniciar estas conclusões finais perguntando como o cinema ocupa o Pátio Humanidades. Afinal, tem-se desafios infra-estruturais para realizar ações de exibição e debate neste espaço. Até agora tem-se construído ações culturais, como as discutidas acima, evitando a projeção em virtude de condições inadequadas para elas ocorrerem. Equipamentos de projeção e som, telão, cadeiras, bem como a rede de internet são fundamentais para tornar o espaço do Pátio Humanidades ocupado pelo cinema, pelas realizações audiovisuais dos estudantes, e ainda as de interesse destes e também da comunidade externa à universidade.

A Aspas Produção Colaborativa se propõe a buscar soluções para que esses dois desafios sejam superados: a estrutura mínima para exibições de filmes seja resolvida e que o debate acerca da cultura audiovisual ocupe o Pátio Humanidades definitivamente. Contudo, sabemos que tanto essa estrutura, quanto o uso deste espaço pela comunidade externa à UFG vai demandar investimentos institucionais, bem como de muito esforço de todos os projetos de extensão envolvidos direta ou indiretamente com o Programa Topofilias. Quanto ao esforço, tem-se neste texto uma parcela do que discentes, docentes e técnicos podem oferecer para a ocupação do Pátio Humanidades. Espera-se, a partir desses resultados, sensibilização da instituição quanto aos investimentos.

\section{REFERÊNCIAS}

ARANTES, Victória. Relatório discente de extensão. Sistema Integrado de Gestão de Atividades Acadêmicas. Universidade Federal de Goiás, 2018.

ALMEIDA, Emilly César de. Relatório discente de extensão. Sistema Integrado de Gestão de Atividades Acadêmicas. Universidade Federal de Goiás, 2018.

BRASIL. Ministério da Educação. Câmara de Educação Superior do Conselho Nacional de Educação. Minuta de Projeto de Resolução. Disponível em: <http://portal. mec.gov.br/docman/setembro-2018-pdf/95681-texto-referencia-audiencia-publica-diretrizes-politica-de-extensao/file>. Acesso em: 9 nov. 2018

BRASIL. Ministério da Educação. Universidade Federal de Goiás. Resolução Consuni, no 3 de 2008. Disponível em: <https://www.proec.ufg.br/up/694/o/Resolucao_CONSUNI_2008_0003.pdf $>$. Acesso em: 9 nov. 2018

DEMO, P. Outro professor: alunos podem aprender bem com professores que aprendem bem. Jundiaí: Paco Editorial, 2011. 160 p. 
DIAS, Natália et al. [Natália Santos Dias; Brunna Alves da Soledade Silva; Emilly Cesar Almeida; Lara Lima Satler]. O conhecimento é coletivo. In: Anais do XX Congresso de Ciências da Comunicação da Região Centro-Oeste, Cuiabá-MT, 2018a. São Paulo: Intercom, 2018a. Disponível em: <http://portalintercom.org.br/anais/centrooeste2018/ expocom/EX61-0157-1.html>. Acesso em: 9 nov. 2018

DIAS, Natália et al. [Natália Santos Dias; Brunna Alves da Soledade Silva; Emilly Cesar Almeida; Lara Lima Satler]. O conhecimento é coletivo. In: Anais do XX Congresso de Ciências da Comunicação Nacional, Curitiba-PR, 2018b. São Paulo: Intercom, 2018b. Disponível em: <http://portalintercom.org.br/anais/nacional2018/expocom/EX610157-1.html>. Acesso em: 9 nov. 2018

FRANCO Jr., Itamar et al. [Ana Karla Santos; Giovanna Villefort; Guilherme Fernandes; Lucas Henrique Valentim; Rute Xavier]. Relatório Discente Produção Cultural na Prática. Produção Cultural, 2018.

GOULART, Amanda et al. [Camila Tavares, Charles Adryel, Victor Moraes, Vinícius Roqueti]. Relatório Discente Produção Cultural na Prática. Produção Cultural, 2018.

LOPES, Fernando et al. [Rodrigo Macedo; Pedro Carneiro; Vitor Falcão; Larissa Jácome; Matheus Aragão]. Relatório Discente Produção Cultural na Prática. Produção Cultural, 2018.

MASSIMINA, Vitória. Relatório discente de extensão. Sistema Integrado de Gestão de Atividades Acadêmicas. Universidade Federal de Goiás, 2018.

MELO, Bruna Toledo de et al. [Estevão Pimenta Barreto Xavier dos Santos; João Pedro Teixeira Moraes; Matheus Fonseca Bolentini; Mônyky Kelly da Silva Barcelos; Thaynara Cardoso de Souza; Wadna da Silva Coelho; Yasmim Martins de Andrade Lobo]. Relatório Discente Produção Cultural na Prática. Produção Cultural, 2018.

PROEC. Extensão Universitária. Texto atualizado em 25 set 2018. Disponível em: <https://www.proec.ufg.br/p/14586-extensao >. Acesso em: 9 nov. 2018

AMUI, Nadja Felix et al. [Nathália Lívia Borges Gonzaga, Vitor Alves Pires]. Relatório Discente Produção Cultural na Prática. Produção Cultural, 2018.

RODRIGUES DA SILVA, Rusvenia Luiza Batista. Topofilia: ações coordenadas na UFG. Sistema Integrado de Gestão de Atividades Acadêmicas, Universidade Federal de Goiás, 2018.

SALES, Ayrton et al. [Guilherme Urbano, Luiz Felipe Neri, Renata Borges, Vitor Lima]. Relatório Discente Produção Cultural na Prática. Produção Cultural, 2018.

STUMPF, Ida Regina C. Pesquisa bibliográfica. In: DUARTE, Jorge \& BARROS, Antonio (Orgs). Métodos e técnicas de pesquisa em comunicação. $2^{\mathrm{a}}$ ed. São Paulo: Atlas, 2008. VILELA, Andressa et al. [Karollina Lopes e Valesca Portilho]. Relatório Discente Produção Cultural na Prática. Produção Cultural, 2018.

Recebido em dezembro de 2018

Aprovado em dezembro de 2018 